\title{
Rehabilitación de las instalaciones eléctricas en los edificios destinados principalmente a viviendas
}

\section{Renovation of electric installations in buildings used mainly as houses}

L. C. Toledano ${ }^{(*)}$, J. Mª de las Casas, C. Bedoya

\section{RESUMEN}

Este trabajo tiene como objetivo difundir la complejidad que conlleva la rehabilitación de las instalaciones eléctricas de un edificio dentro de la rehabilitación integral de los mismos, así como la normativa que la regula y que el proyectista, y posteriormente el instalador electricista que realiza la obra, deben de cumplir.

\begin{abstract}
A la hora de pensar en la rehabilitación de la instalación eléctrica de un edificio debemos plantearnos que es lo que se va a rehabilitar y cual va a ser el uso de esas instalaciones después de la rehabilitación, teniendo presente que el trabajo que se realice tiene que ser de utilidad al menos para $30-50$ años.
\end{abstract}

\begin{abstract}
Se hace un repaso de todas las partes que componen las instalaciones eléctricas de enlace de un edificio, normativa a aplicar y forma de ejecución. En las instalaciones interiores de las viviendas se describen los circuitos que como mínimo se deben ejecutar de acuerdo con el reglamento electrotécnico para baja tensión de 2002, actualmente en vigor, y que habilitan a esas viviendas para el nivel de electrificación que requieren actualmente las viviendas.
\end{abstract}

Los trabajos de rehabilitación de instalaciones eléctricas requieren un manejo importante de la legislación actual, tanto a nivel nacional como autonómica, y una gran experiencia en cómo aplicar esta norma en los edificios, por cuyas características debemos conservar, haciendo unas instalaciones que no deterioren el edificio en su conjunto ni en sus partes más significativas.

\section{$329-4$}

Palabras clave: Edificios, Viviendas, Rehabilitación, Instalaciones eléctricas, Normativa.

\section{SUMMARY}

The objective of the present work is to report about the complexity of the renovation of the electric installation of a building, in the frame of a entire building renovation. We will also discuss the regulations that must be taken into account in the project and that the electrician will have to follow.

During the design of the renovation of the electric installation of a building, it is necessary to consider what we want to renovate and which use will be given to the building afterwards. Further, the work must be intended for, at least, 30 to 50 years of utilization.

We have also made a review of all the components of the connection installation in a building, applying regulations and way of implementation. About the interior electric equipment of housings, it is described the circuits that must be implemented in any case according to the low voltage regulation from 2002, presently in effect. These circuits fit out the buildings for the electrification currently needed in housings.

The renovation works in electric installations require good management of the present regulations, both national and regional, and wide experience on how to apply them in each case. Note that the characteristics of the buildings must be preserved and the renovation work must not cause the building as a whole or its more significant parts to deteriorate.

Keywords: Buildings, Houses, Renovation, Electric installation, Regulations. 
1. Antigua protección general a base de hilo de cobre.

2. Centralización de contadores a rehabilitar

\section{INTRODUCCIÓN}

En este trabajo se va a abordar la rehabilitación eléctrica de los edificios destinados principalmente a viviendas y se pretende elaborar una pequeña guía que facilite la labor de los arquitectos, aparejadores y arquitectos técnicos y de los directores de obra en general, para establecer un diagnóstico de las instalaciones eléctricas existentes que permita analizar objetivamente las mismas y facilitar la labor de diseño de la rehabilitación de las mismas.

Se va a seguir los criterios del nuevo Reglamento Electrotécnico para Baja Tensión, Real Decreto 842/2002 de 2 de agosto y publicado en el BOE $n^{\circ} 224$ de fecha 18 de septiembre de 2002, pues según reza en el Real Decreto la entrada en vigor del Reglamento Electrotécnico para Baja Tensión fue el 18 de septiembre de 2003, si bien se podía aplicar de forma voluntaria desde el 18 de septiembre de 2002.

En ocasiones, al planificar la rehabilitación integral de un edificio, la posibilidad real de mantener siquiera una mínima parte de la instalación eléctrica original es prácticamente nula, y se prescinde de todas las instalaciones eléctricas existentes.En este caso se debe de considerar, a todos los efectos, como una instalación eléctrica nueva, aplicando la normativa existente como si fuera instalación de nueva ejecución.

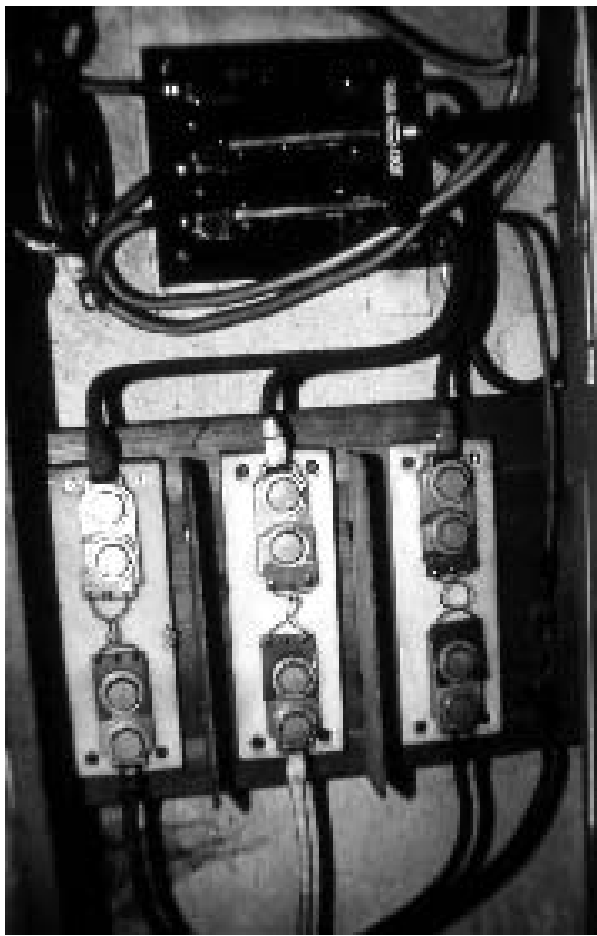

Cuando se utiliza parte de la instalación eléctrica o el edificio a rehabilitar se mantiene en su estructura fundamental, es cuando hay que adecuar una nueva instalación eléctrica a ese edificio y es cuando se dice que se rehabilitan las instalaciones eléctricas del edificio. En este caso se aplica la reglamentación vigente, con flexibilidad para adecuarla al edifico que se va a rehabilitar, contando con la colaboración de los técnicos de la empresa eléctrica de la zona a la hora de aplicar sus normas particulares, y, en su caso, de discrepancia, con la Dirección General o Delegación Provincial de Industria de la Comunidad Autónoma correspondiente.

Cuando se decide realizar la rehabilitación eléctrica de un edificio destinado principalmente a viviendas, hay que plantearse, en primer lugar, la rehabilitación como un proyecto, conocer las normas de la empresa eléctrica suministradora en la zona, conocer la reglamentación eléctrica en la Comunidad donde se va a hacer la rehabilitación y diseñarlo y hacer el cálculo de la instalación de enlace correspondiente.

Todo ello se puede resumir en la Tabla 1

La nueva instalación que salga del estudio y la adecuación a las características del edificio se basará en la versatilidad de la misma, que pueda ser capaz de solucionar todas las necesidades energéticas del edificio, la posi-

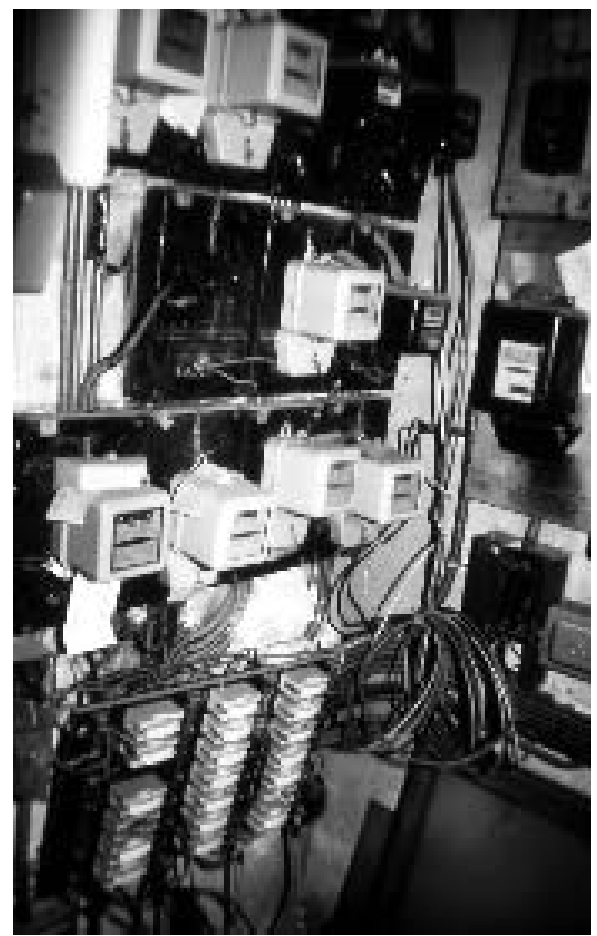


Tabla 1

Elemento a tener en cuenta en la rehabilitación eléctrica

\begin{tabular}{|c|c|c|}
\hline La Rehabilitación & Para qué sirve o a dónde va destinada & \begin{tabular}{|l} 
Viviendas \\
Locales comerciales \\
Oficinas \\
Zonas comunes interiores \\
Zonas comunes exteriores \\
Garajes
\end{tabular} \\
\hline & Qué hay que rehabilitar & $\begin{array}{l}\text { Acometidas } \\
\text { Caja general de protección } \\
\text { Línea General de Alimentación } \\
\text { Elementos para la Ubicación de } \\
\text { Contadores } \\
\text { Derivaciones individuales } \\
\text { Caja para Interruptor de control de } \\
\text { potencia } \\
\text { Dispositivos generales de Mando y } \\
\text { Protección } \\
\text { Instalación interior } \\
\text { Puesta a tierra }\end{array}$ \\
\hline \multirow[t]{4}{*}{ Reglamentación } & $\begin{array}{l}\text { En el ámbito de la administración } \\
\text { central }\end{array}$ & $\begin{array}{l}\text { Reglamento Electrotécnico para Baja } \\
\text { Tensión } \\
\text { Real Decreto de Distribución } \\
\text { (Acometidas, Verificaciones, etc.) } \\
\text { Decreto Tarifas eléctricas } \\
\end{array}$ \\
\hline & En el ámbito autonómico & $\begin{array}{l}\text { Aplicación práctica de los reglamentos } \\
\text { Normas autonómicas } \\
\end{array}$ \\
\hline & En el ámbito local & \begin{tabular}{|l|} 
Normas sobre seguridad \\
Normas de protección civil \\
\end{tabular} \\
\hline & A nivel empresa eléctrica & $\begin{array}{l}\text { Normas particulares de la Empresa } \\
\text { eléctrica distribuidora }\end{array}$ \\
\hline \multirow[t]{3}{*}{ Acometida } & Tramitación administrativa & $\begin{array}{l}\text { Petición de la acometida } \\
\text { Trámites con la empresa eléctrica de } \\
\text { distribución } \\
\text { Trámites con la Delegación de } \\
\text { industria de la Comunidad Autónoma } \\
\text { correspondiente } \\
\text { Permisos municipales } \\
\end{array}$ \\
\hline & Tipo de acometida & $\begin{array}{l}\text { Acometida provisional de obra } \\
\text { - Utilización de la antigua } \\
\text { - Aumento de potencia } \\
\text { Acometida definitiva } \\
\text { - Válida la antigua } \\
\text { - Válida parcialmente la antigua } \\
\text { - No válida la antigua } \\
\end{array}$ \\
\hline & Centro de transformación & $\begin{array}{l}\text { Potencia inferior a } 100 \mathrm{~kW} \\
\text { Potencia superior a } 100 \mathrm{~kW} \\
\text { - Potencia } \\
\text { - Ubicación }\end{array}$ \\
\hline Previsión de cargas & $\begin{array}{l}\text { Cálculo de la previsión de la potencia } \\
\text { prevista para el edificio }\end{array}$ & $\begin{array}{l}\text { Potencia de viviendas } \\
\text { - Grado electrificación } \\
\text { - Equipamiento } \\
\text { - Simultaneidad } \\
\text { Potencia locales comerciales } \\
\text { Potencia de oficinas } \\
\text { Potencia servicios generales } \\
\text { Potencia aparatos elevadores } \\
\text { Potencia garaje } \\
\text { Potencia otros servicios } \\
\end{array}$ \\
\hline \multirow[t]{2}{*}{ Instalaciones de enlace } & $\begin{array}{l}\text { Instalaciones que precisan aprobación } \\
\text { previa de proyecto }\end{array}$ & $\begin{array}{l}\text { Proyecto } \\
\text { Ejecución y Seguimiento } \\
\text { Boletín del instalador }\end{array}$ \\
\hline & Ampliaciones & $\begin{array}{l}\text { Aumento de la Potencia superior a } \\
50 \% \text { de la instalada } \\
\text { - Como si fuera nueva } \\
\text { Si es inferior a } 50 \% \text { de la instalada: } \\
\text { Boletines } \\
\end{array}$ \\
\hline Instalación interior & $\begin{array}{l}\text { Diseño y dimensionado de los } \\
\text { diferentes circuitos según utilización }\end{array}$ & $\begin{array}{l}\text { Instalaciones de la vivienda } \\
\text { Instalaciones zonas comunes } \\
\text { Instalaciones de locales } \\
\text { Instalaciones de oficinas } \\
\text { Instalaciones de elevadores }\end{array}$ \\
\hline $\begin{array}{l}\text { Guía para el diagnóstico de las } \\
\text { instalaciones eléctricas }\end{array}$ & Lista de operaciones & $\begin{array}{l}\text { Instalaciones de enlace } \\
\text { Instalaciones comunitarias } \\
\text { Instalación interior. de la vivienda } \\
\text { Instalación interior de locales y oficinas } \\
\text { Instalación de los aparatos elevadores } \\
\text { Instalaciones de tierra }\end{array}$ \\
\hline
\end{tabular}


bilidad de ampliación y sobre todo garantizar la seguridad de las personas y la integridad de las instalaciones y de los receptores.

La reglamentación que se debe seguir a la hora de diseñar una rehabilitación de edificios es:

- Reglamento Electrotécnico para Baja Tensión. Real Decreto 842/2002 de 2 de agosto

- Reglamento de Distribución, comercialización y autorización de instalaciones de energía eléctrica. Real Decreto 1955/2000 de 1 de diciembre

- Código Técnico de la Edificación

- Normas particulares de empresas eléctricas aprobadas por el MINER y por las Comunidades Autónomas correspondientes

- Guía práctica de aplicación del Reglamento para baja tensión, difundido por el Ministerio de Industria a través de su página Web.

A continuación se describen algunos de los factores que pueden ser de más utilidad para el proyectista.

\section{GRADOS DE ELECTRIFICACIÓN DE LAS VIVIENDAS EN LOS EDIFICIOS DESTINADOS PRINCIPALMENTE A VIVIENDAS}

Es necesario saber qué se va a rehabilitar y cómo. Es necesario saber el equipamiento que se van a dar a las viviendas o a los locales o a las oficinas, en fin al conjunto del edificio.

En este apartado se desarrolla la ITC-BT 10 del reglamento para baja tensión de 2002 aplicado a los edificios de viviendas, pero dentro del ámbito de las instalaciones eléctricas en edificios.

\subsection{Sistema de distribución para edificios}

Se establecen los siguientes lugares de consumo:

- Edificios destinados principalmente a viviendas

- Edificios comerciales o de oficinas

- Edificios destinados a una industria específica

- Edificios destinados a una concentración de industrias

\subsection{Grados de electrificación de una vivienda}

En primer lugar conoceremos los denominados GRADO DE ELECTRIFICACION que han sufrido un cambio importante respecto del Reglamento de 1973. Leyendo el Reglamento la instrucción ITC-BT 10 extraemos los siguientes párrafos:

- Electrificación básica

Es la necesaria para la cobertura de las posibles necesidades de utilización primarias sin necesidad de obras posteriores de adecuación.

Debe permitir la utilización de los aparatos eléctricos de uso común en una vivienda.

- Electrificación elevada

Es la correspondiente a viviendas con una previsión de utilización de aparatos electrodomésticos superior a la electrificación básica o con previsión de utilización de sistemas de calefacción eléctrica o acondicionamiento de aire o con superficies útiles de las viviendas superiores a $160 \mathrm{~m}^{2}$, o con cualquier combinación de los casos anteriores.

Una vez definido los grados de electrificación necesitamos conocer la previsión de cargas del edificio, teniendo en cuenta que para las nuevas construcciones la potencia de una vivienda no será inferior a $5.750 \mathrm{~W}$ a 230 V para electrificación básica y 9.200 W. a $230 \mathrm{~V}$ en electrificación elevada.

Se puede resumir el grado de electrificación y la previsión de la potencia en las viviendas en la Tabla 2

\subsection{Determinación del grado de electrificación}

El grado de electrificación de las viviendas se define por el promotor o el proyectista de acuerdo con:

a) Equipamiento básico que cubra las posibles necesidades de utilización primarias sin necesidad de posteriores obras de adecuación: Iluminación, cocinado, lavadora, lavavajillas, etc. La previsión de potencia no será inferior a $5.750 \mathrm{~W}$ a $230 \mathrm{~V}$.

Tabla 2

Grado de electrificación

\begin{tabular}{|l|c|c|c|}
\hline Grado & Potencia & Tensión & Superficie \\
\hline Básico & $\leq 5.750 \mathrm{~W}$ & $230 \mathrm{~V}$. & hasta $160 \mathrm{~m}^{2}$ \\
\hline Elevado & $\leq 9.200 \mathrm{~W}$ & $230 \mathrm{~V}$. & superior a $160 \mathrm{~m}^{2}$ \\
\hline
\end{tabular}


b) Equipamiento elevado, donde además del equipamiento básico se prevea la instalación de calefacción, aire acondicionado, etc., o la superficie de la vivienda es superior a 160 $\mathrm{m}^{2}$. La previsión de potencia no será inferior a $9.200 \mathrm{~W}$ a $230 \mathrm{~V}$.

\subsection{Grado de electrificación proyectado}

De acuerdo con lo indicado en el apartado anterior, se tratará de determinar el grado de electrificación siguiendo los criterios mencionados (se adoptará el grado mayor obtenido).

a) por dotación de equipos eléctricos (lavadora, calefacción, aire acondicionado, etc.)

b) Por superficie útil de la vivienda

c) Por otros equipamientos

\section{PREVISIÓN DE CARGAS DE UN EDIFICIO}

\subsection{Cálculo de la previsión de cargas}

A la hora de calcular la previsión de cargas de un edificio destinado principalmente a viviendas se tendrán en cuenta las potencias que pueden demandar los diferentes componentes de la instalación: viviendas, locales comerciales, oficinas, servicios generales de la finca, ascensores y montacargas, garaje, etc.

En el caso de la previsión de cargas correspondientes a las viviendas se permite la aplicación de coeficientes de simultaneidad; en el resto de los servicios o aplicaciones no. La carga total correspondiente a un conjunto de viviendas se obtendrá multiplicando la potencia máxima prevista para las viviendas por el coeficiente de simultaneidad, Tabla 3, según el número de viviendas. La previsión total de cargas de un edificio de viviendas, según la instrucción ITC BT 25, del Reglamento de Baja Tensión, será la suma de:

- Previsión de la potencia de viviendas, según el grado de electrificación o según el equipamiento que se va a instalar: calefacción eléctrica, bomba de calor, lavadora, lavavajillas, secadora, etc. Si en la vivienda se prevé que haya calefacción eléctrica por acumulación no pueden aplicarse coeficientes de simultaneidad.

- Previsión de la potencia de los locales comerciales, con un mínimo de $100 \mathrm{~W}$ por $\mathrm{m}^{2}$.

- Previsión de la potencia de oficinas, con un mínimo de 100 o $125 \mathrm{~W}$ por $\mathrm{m}^{2}$

- Previsión de los servicios generales de la finca. En este punto se deben de sumar
Tabla 3

Coeficientes de simultaneidad según el número de viviendas

\begin{tabular}{|l|l|}
\hline Número de viviendas & Coeficiente de simultaneidad \\
\hline 1 & 1 \\
\hline 2 & 2 \\
\hline 3 & 3 \\
\hline 4 & 3,8 \\
\hline 5 & 4,6 \\
\hline 6 & 5,4 \\
\hline 7 & 6,2 \\
\hline 8 & 7 \\
\hline 9 & 7,8 \\
\hline 10 & 8,5 \\
\hline 11 & 9,2 \\
\hline 12 & 9,9 \\
\hline 13 & 10,6 \\
\hline 14 & 11,3 \\
\hline 15 & 11,9 \\
\hline 16 & 12,5 \\
\hline 17 & 13,1 \\
\hline 18 & 13,7 \\
\hline 19 & 14,3 \\
\hline 20 & 14,8 \\
\hline 21 & 15,3 \\
\hline & $15,3+(\mathrm{n}-21) 0,5$ \\
\hline & \\
\hline
\end{tabular}

las potencias previstas para la iluminación del portal y de la escalera (a razón de 10 $\mathrm{W} / \mathrm{m}^{2}$ en iluminación fluorescente), depuradoras de piscinas (a razón de $10 \mathrm{~W} / \mathrm{m}^{3}$ ), iluminación de trasteros, calefacción y aire acondicionado si lo hubiera, etc.

- Previsión de potencia de ascensores y montacargas, según velocidad, capacidad de carga y paradas (se recomienda poner la potencia indicada por fabricantes aumentada en un $10 / 15 \%$ para compensar la intensidad de arranque cuando exista un solo ascensor en la finca)

- Previsión de potencia de garajes, a razón de $20 \mathrm{~W} / \mathrm{m}^{2}$ para iluminación y ventilación forzada

Esta previsión de carga, en kW, será la que necesitaremos para el edificio. Como el edificio ya existía y tenía una acometida, la petición de aumento de potencia de acometida a la empresa eléctrica será por la diferencia entre el cálculo realizado y la potencia que tenía la antigua acometida.

El coste de la acometida que nos demandará la empresa eléctrica será sobre esa diferencia de aumento de potencia, ya que los derechos que se pagaron en su día por la antigua acometida están adscritos a la instalación y, por lo tanto, no hay que volverlos a pagar.

Como ejemplo resumen: edificio a rehabilitar de 7 viviendas antiguas con $3 \mathrm{~kW}$ de previsión de carga cada una, un local de $5 \mathrm{~kW}$ y servicios generales de la finca de $3 \mathrm{~kW}$, que contaba con una acometida de 29 kW.

El nuevo edificio dispone de 5 viviendas de 9 kW cada una, dos locales de 10 kW cada uno y unos servicios generales para la finca 
de 10 kW, en total la previsión de cargas es de $75 \mathrm{~kW}$.

La demanda de aumento de potencia a la empresa eléctrica será de $75-29=56$ kW y se pagarán los derechos de acometida por esos 56 kW, nada más.

\subsection{Reserva de local para Centro de Transformación}

Una vez conocida la previsión total de cargas correspondiente al edificio en cuestión el siguiente paso, y muy importante, a tener en cuenta antes de continuar, es ver si es necesario reservar un local para la instalación de un centro de transformación

En el artículo 13 del Reglamento Electrotécnico para Baja Tensión 2002, se establece que se seguirán las prescripciones recogidas en la reglamentación por el que se regulan las actividades de transporte, distribución, comercialización, suministro y procedimiento de autorización de instalaciones de energía eléctrica de 2000.

En el artículo 47 (cuotas de extensión y acceso) punto 5 dice textualmente:

"5. Cuando se trate de suministros en suelo urbano con la condición de solar, incluidos los suministros de alumbrado público, y la potencia solicitada para un local, edificio o agrupación de éstos sea superior a 100 kW, o cuando la potencia solicitada de un nuevo suministro o ampliación de uno existente sea superior a esa cifra, el solicitante deberá reservar un local para su posterior uso por la empresa distribuidora, de acuerdo con las condiciones técnicas reglamentarias y con las normas técnicas establecidas por la empresa distribuidora y aprobadas por la Administración competente, cerrado y adaptado, con fácil acceso desde la vía pública, para la ubicación de un centro de transformación cuya situación corresponda a las características de la red de suministro aérea o subterránea y destinado exclusivamente a la finalidad prevista."

La empresa distribuidora, cuando haga uso del mencionado local deberá abonar al propietario una compensación.

\section{INSTALACIONES DE ENLACE}

Se denominan instalaciones de enlace aquéIlas que unen la caja general de Protección o cajas Generales de Protección, incluidas éstas, con las instalaciones interiores o receptoras del usuario. Ésta es la parte más importante a la hora de hacer la rehabilitación eléctrica de un edificio y donde el profesional de las instalaciones, con su experiencia, adecúa las normas de instalación actuales al edificio a rehabilitar. En ningún caso la ejecución tiene que suponer un deterioro del edifico a rehabilitar sino adaptarse al edificio.

En caso de discrepancias del proyectista o el instalador electricista con la empresa eléctrica a la hora de hacer la instalación de enlace, se puede recurrir a la Delegación provincial de industria o a la Dirección General de Industria de la Comunidad correspondiente para que actúe de moderador y dictamine la ejecución más conveniente.

\subsection{Partes de la instalación de enlace}

La Instalación de enlace de un edificio destinado principalmente a viviendas consta de las siguientes partes:

\section{Acometida}

Caja general de protección

Línea general de alimentación

Centralización de contadores

Derivación individual

Caja de ICP

Cuadro General de Mando y Protección

Puesta a tierra

- Acometida (no forma parte literalmente de las instalaciones de enlace pero incluiremos su definición y sus características ya que forma una parte indisoluble de la instalación eléctrica del edificio): es la línea que une la red de distribución de la empresa eléctrica con la caja general de protección. Suele ser de aluminio y realiza la instalación la empresa eléctrica o la propiedad del edificio (a negociar, pero siempre por una empresa homologada). Será aérea o subterránea en función de como sea la red de distribución de la empresa eléctrica. En los cascos urbanos se debe de realizar subterránea. La acometida, por lo general, queda en propiedad de la empresa eléctrica.

- Caja General de Protección, es el primer elemento propiedad del cliente o de la comunidad de propietarios, que alberga los fusibles de protección del las Líneas Generales de Alimentación del edificio. Consta de tres bases porta-fusibles para colocar los fusibles de protección de cada una de las tres fases y una pletina de neutro. Se coloca una caja por cada $160 \mathrm{~kW}$ de potencia prevista o fracción. La caja está normalizada por UNESA por la norma 1403, es de grado de protección IP43 según UNE 20324 e IK 08 según UNE - EN 50102 y está prevista para colocarse a la intemperie o colocada dentro de armarios o mechinales.

En la rehabilitación se suelen fabricar de armarios ad hoc, para colocar las cajas generales de protección, con cerraduras normalizadas, y siempre que sea posible se 


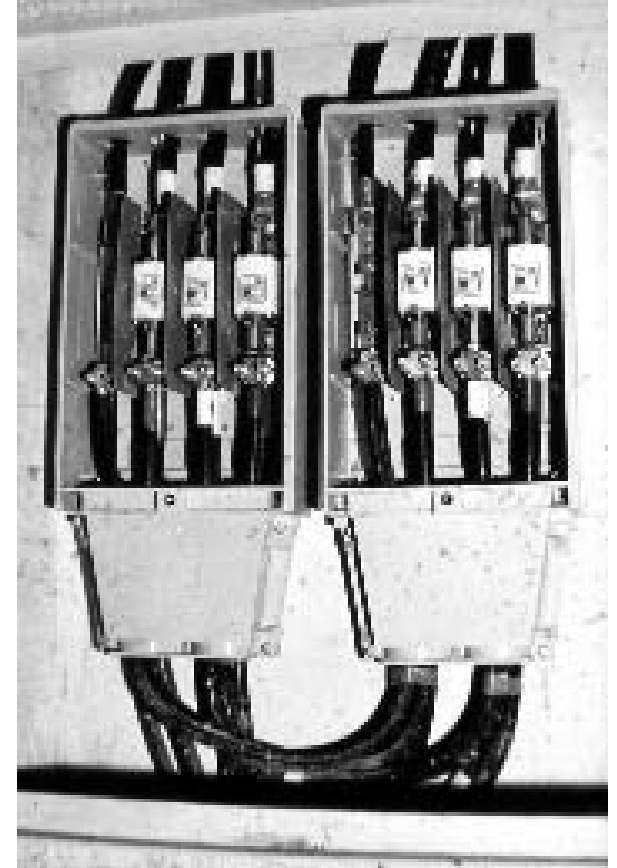

colocará en el exterior del edifico para que se pueda acceder a ella sin dificultad, pero sin deteriorar la fachada en ningún caso.

- Línea general de alimentación, es la parte de la instalación de enlace que une la caja general de protección con el emplazamiento de contadores (centralización de contadores). Puede ser de cobre o aluminio (por lo general de cobre) con un nivel de aislamiento de $0,6 / 1 \mathrm{kV}$. y circula por lugares de uso común. Se dimensiona de acuerdo con la potencia total de previsión de carga del edificio y la longitud de la misma (caída de tensión y densidad de corriente).

- Centralización de contadores (Ubicación de contadores)), es el módulo en el que se colocan los elementos de medida y protección y que alberga las siguientes unidades funcionales:

1. Unidad funcional de interruptor general de maniobra, cuya misión es dejar sin servicio toda la centralización de contadores en caso de necesidad.

2. Unidad funcional de embarrado general y fusibles de seguridad (los fusibles de protección de las derivaciones individuales).

3. Unidad funcional de medida, con los elementos de medida de los diferentes usuarios. Contadores y equipos de medida.

4. Unidad funcional de embarrado de protección y bornes de salida (los embarrados de protección de la red de tierra para cada abonado).
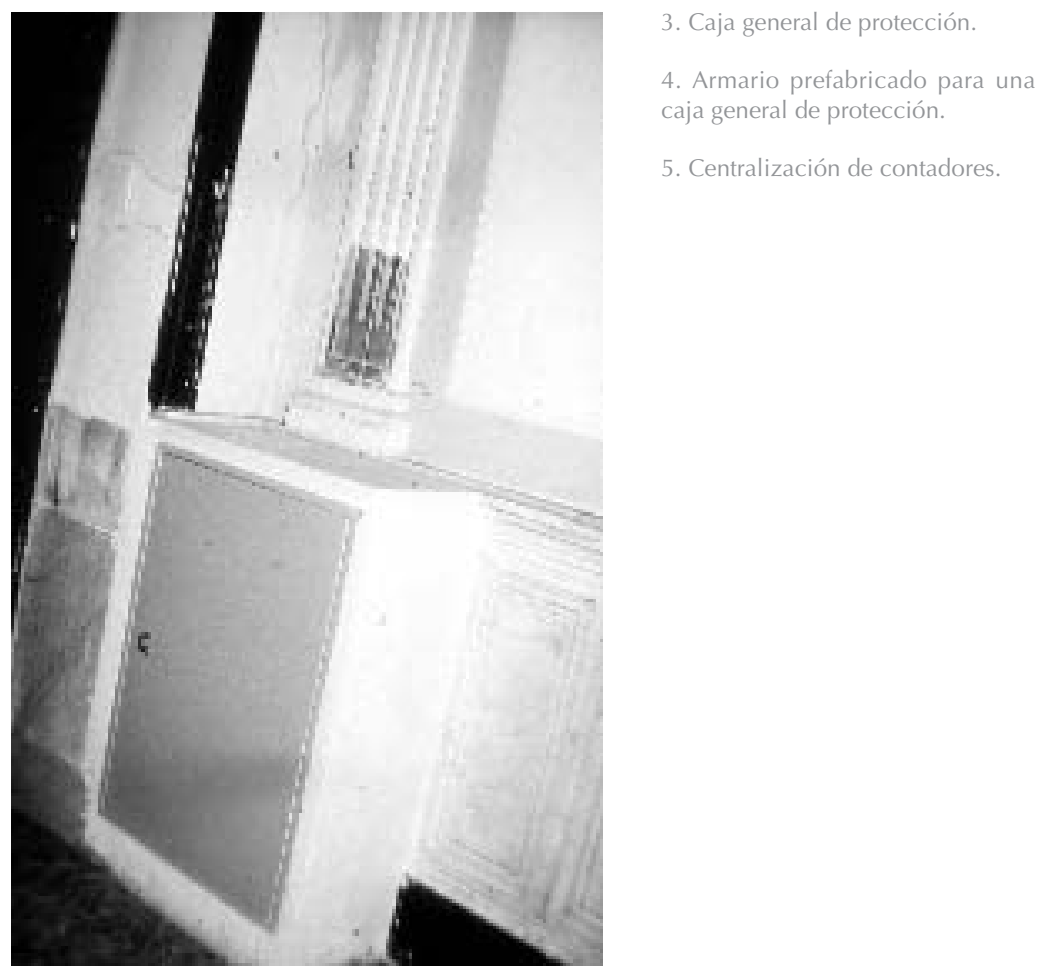

5. Centralización de contadores.

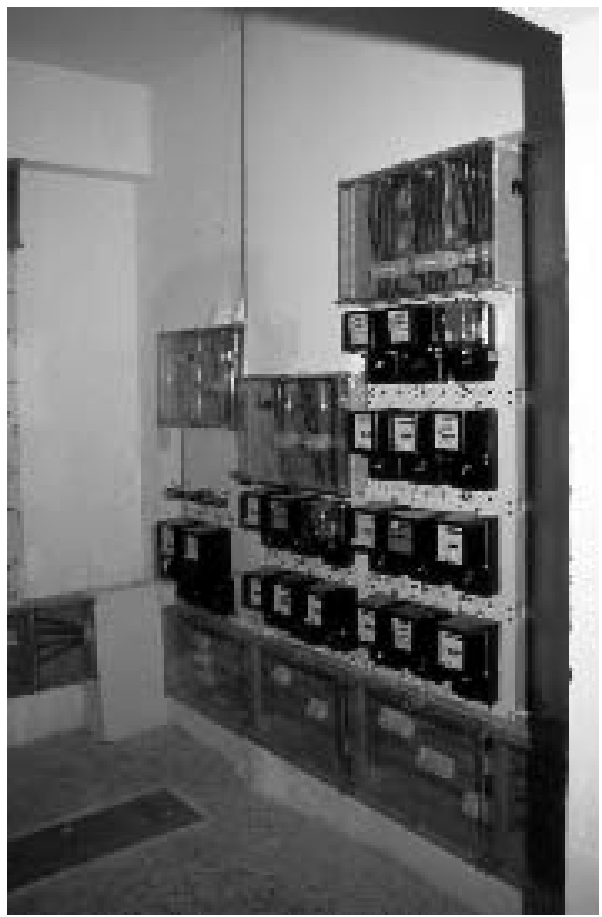

En el nuevo reglamento se contemplan también:

5. Unidad funcional de mando, para el cambio de tarifa de cada abonado (opcional).

6. Unidad funcional de telecomunicaciones (opcional). 

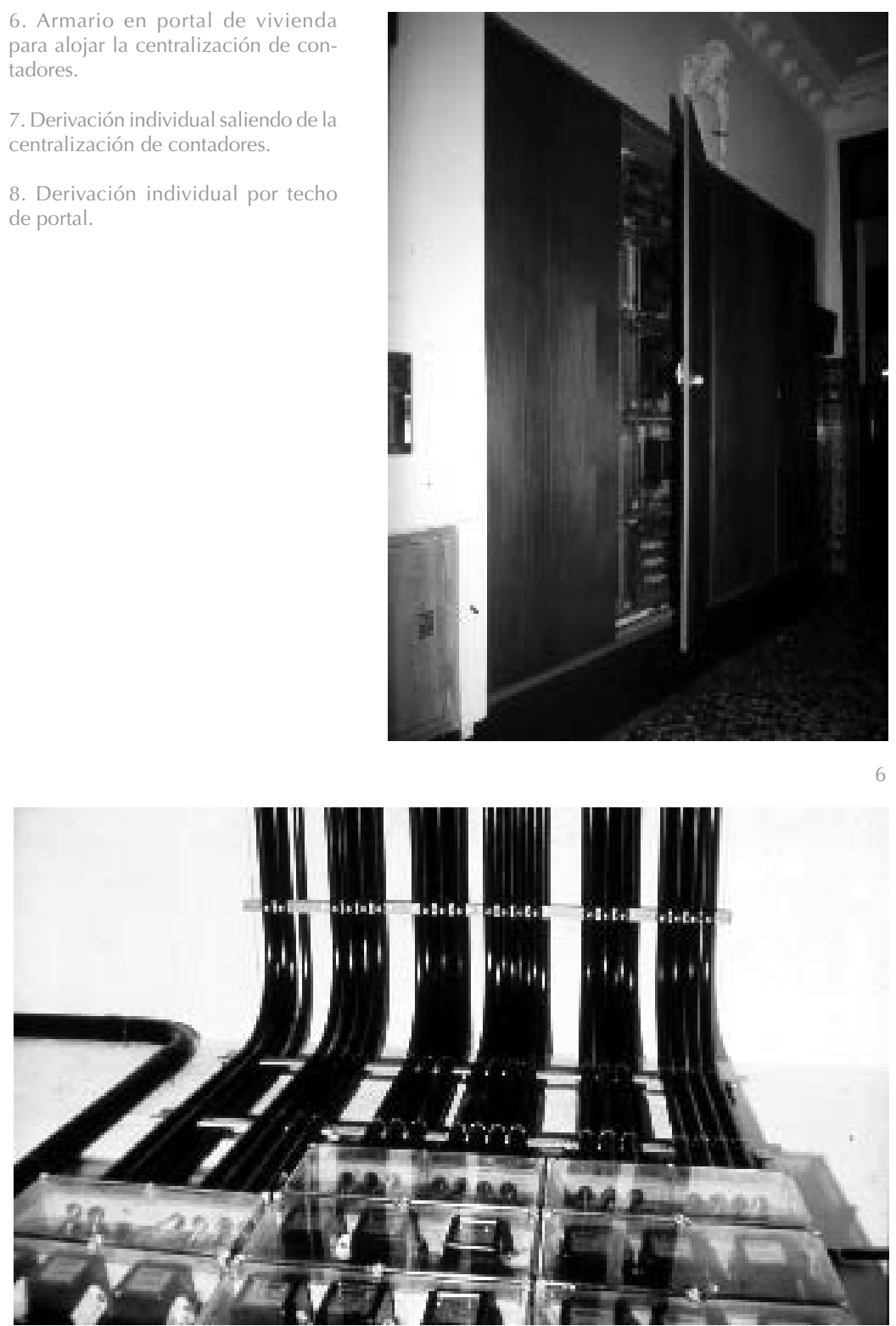

Puede colocarse en cuartos específicos de contadores, o si la rehabilitación no lo permite, se pueden fabricar armarios en el portal del edificio, en los descansillos de la escalera, debajo del hueco de escaleras, en una habitación de la antigua vivienda del portero, etc., pero siempre con acceso desde lugares comunes del edificio.

- Derivación individual, es la línea que partiendo de la ubicación o concentración de contadores, suministra energía eléctrica a una instalación de usuario, y acaba en el cuadro general de mando y protección. Estará compuesto por los conductores de fase, el neutro, el de protección y el cable de mando para la discriminación horaria. Circula por lugares de uso común y va entubada.

- Interruptor de control de potencia. Cuadro general de mando y protección: es el

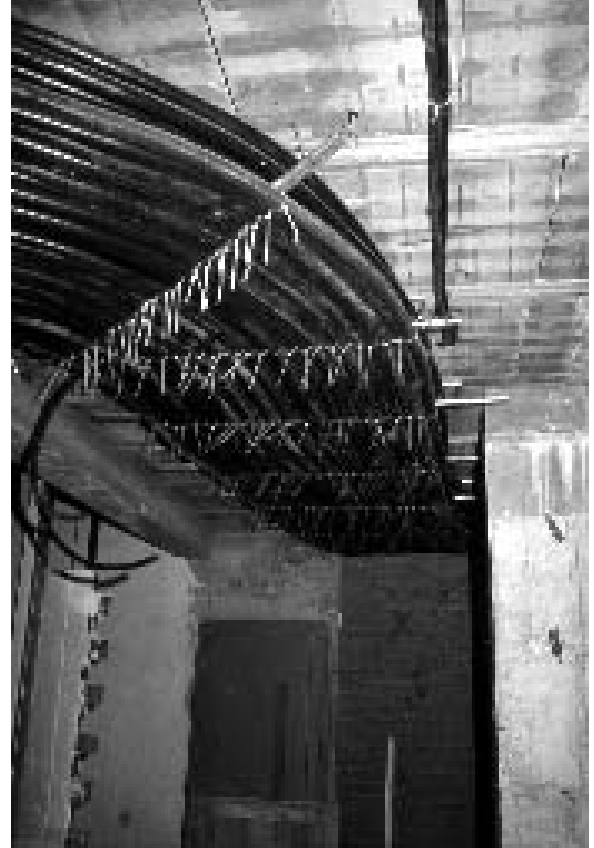

primer elemento de la instalación interior del usuario y es donde se instala la caja para el Interruptor de Control de Potencia ICP (necesario por exigencia de la aplicación de la tarifa a aplicar), y se colocan todos los mecanismos de mando, control y seguridad del suministro.

El cuadro general de mando y protección consta de un interruptor general, uno o varios interruptores diferenciales de alta sensibilidad $(30 \mathrm{~mA})$, varios interruptores magnetotérmicos, y cualquier otro mecanismo que comande los circuitos interiores como relojes horarios, racionalizadores de consumo, elementos domóticos, protección contra sobre tensiones, etc.

- Puesta a tierra: instalación de seguridad que une todos los puntos de luz, tomas de corriente, carcasas de electrodomésticos y masas significativas que puedan existir en el edificio, con un conjunto de electrodos colocados en el terreno, con el fin de evitar la aparición de potenciales peligrosos entre estos elementos y el terreno y descargar a tierra cualquier derivación eléctrica o descarga de origen atmosférico. La instalación de puesta a tierra, junto con los diferenciales de alta sensibilidad, es la mejor garantía de seguridad de las personas y de los animales.

Al rehabilitar un edificio no tenemos la solución de colocar la red de tierras en la cimentación del edificio, por lo que se tendrá que buscar soluciones alternativas donde colocar las picas de tierra (electrodo más común para realizar la puesta a tierra en edificios existentes). 


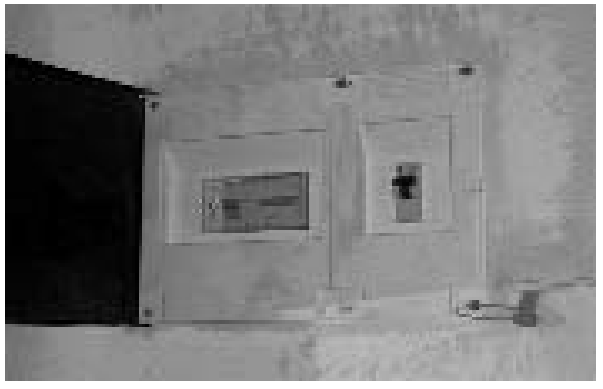

Las picas se ubicarán en los patios de luces o en los sótanos del edificio, unidas unas con otras con cable de cobre desnudo de $35 \mathrm{~mm}$, y se llevarán al punto de puesta a tierra. Una vez colocadas las picas y conectadas entre sí es conveniente hacer mediciones para conocer el valor de la resistencia de paso a tierra. Si es alto se colocan más picas hasta que se obtengan los valores deseados (Inferior a 37 ohmios. Este valor puede variar según la comunidad autónoma). En ocasiones es necesario mejorar el valor de la resistencia de paso a tierra tratando el

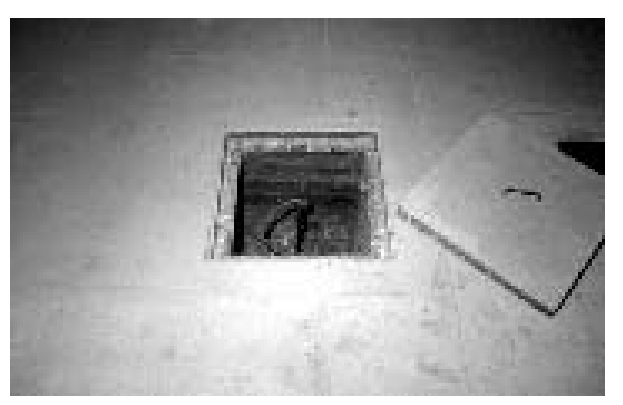

9. Cuadro general de mando y protección en vivienda rehabilitada.

10. Registro de la red de tierra. Pica de tierra. terreno, con sales o geles, allí donde se colocan las picas.

\subsection{Defectos más corrientes de las instala- ciones de enlace}

Antes de hacer el proyecto de rehabilitación eléctrica es conveniente revisar la instalación existente para conocer los puntos concretos a rehabilitar, si se pueden aprovechar partes de la instalación o si es necesario rehabilitarla entera. En la Tabla 4 se resumen los defectos más corrientes de cada uno de los elementos

Tabla 4

Defectos más corrientes de las instalaciones de enlace antiguas

\begin{tabular}{|c|c|}
\hline Acometida & $\begin{array}{l}\text { Sección insuficiente } \\
\text { Falta de aislamiento } \\
\text { Sin protección mecánica }\end{array}$ \\
\hline Caja General Protección & $\begin{array}{l}\text { No existe } \\
\text { Sobre tableros de madera } \\
\text { No tiene fusibles }\end{array}$ \\
\hline Línea General de Alimentación & $\begin{array}{l}\text { Sección insuficiente } \\
\text { Falta de aislamiento } \\
\text { Sin protección mecánica } \\
\text { Conexiones por retorcimiento, empalmes inadecuados } \\
\text { Circula por lugares privativos }\end{array}$ \\
\hline Centralización contadores & $\begin{array}{l}\text { No existe, contadores en las viviendas y locales } \\
\text { Contadores sobre elementos de madera, etc. } \\
\text { Falta de fusibles de seguridad } \\
\text { Colocados en lugares húmedos, de difícil acceso, con otras instalaciones o } \\
\text { servicios, en lugares privativos ( vivienda de los porteros ) }\end{array}$ \\
\hline Derivaciones individuales & $\begin{array}{l}\text { No existen } \\
\text { Por lugares de uso privado } \\
\text { Empalmes por retorcimiento }\end{array}$ \\
\hline Caja ICP & $\begin{array}{l}\text { Ausencia de la caja } \\
\text { Colocación en los paneles de los contadores }\end{array}$ \\
\hline Cuadro General Mando y Protección & $\begin{array}{l}\text { No existe } \\
\text { No existe diferencial } \\
\text { Existencia de fusibles } \\
\text { Interruptor de accionamiento manual } \\
\text { Diferencial que no es de alta sensibilidad } \\
\text { Un solo automático para toda la instalación interior } \\
\text { Automáticos unipolares } \\
\text { Automáticos infradimensionados } \\
\text { Ausencia de Interruptor general automático }\end{array}$ \\
\hline Puesta a tierra & $\begin{array}{l}\text { Ausencia de puesta a tierra } \\
\text { Interrupción del circuito de tierras } \\
\text { Mala conservación de la puesta a tierra } \\
\text { Secciones insuficientes } \\
\text { Ausencia de los conductores de protección }\end{array}$ \\
\hline
\end{tabular}


que componen las instalaciones de enlace, entendiéndose que pueden darse uno, varios, todos o ninguno, porque cada instalación es un caso distinto y también la solución será un caso distinto:

\section{INSTALACIONES INTERIORES}

\subsection{Introducción}

Son las instalaciones que partiendo del cuadro general de mando y protección llevan la energía eléctrica a todos los puntos de luz y tomas de corriente de los locales o de las viviendas.

El número de circuitos estará en función del grado de electrificación, del equipamiento de electrodomésticos que posea la vivienda o el local, del nivel de confort que se quiera dar a la vivienda, etc. pero como mínimo los circuitos que se establecen en la instrucción ITC - BT 25 de Reglamento para baja tensión.

Por lo general se deberán prever los siguientes circuitos, con las siguientes secciones y protecciones, según equipamiento, Tabla 5.

Los tipos de circuitos independientes que se definen en el RBT instrucción ITC - BT 25, del C1 al C11, son los que se indican a continuación y estarán protegidos cada uno de ellos por un interruptor automático de corte omnipolar con accionamiento manual (protección contra sobrecargas y cortocircuitos), con una intensidad asignada según tipo de circuito.

\subsection{Circuitos}

Los circuitos correspondientes a cada uno de los grados de electrificación son los siguientes:

\subsubsection{Electrificación básica}

Las viviendas con este grado de electrificación su instalación eléctrica estará compuesta por los siguientes circuitos:
- C1 Circuito de distribución interna, destinado a alimentar los puntos de Iluminación

- C2 Circuito de distribución interna, destinado a tomas de corriente de uso general y frigorífico

- C3 Circuito de distribución interna, destinado a alimentar la cocina y el horno

- C4 Circuito de distribución interna, destinado a alimentar la lavadora, lavavajillas y termo eléctrico

- C5 Circuito de distribución interna, destinado a alimentar tomas de corriente de los cuartos de baño, así como las bases auxiliares del cuarto de cocina.

\subsubsection{Electrificación elevada}

Es el caso de las viviendas con una previsión importante de aparatos electrodomésticos que obligue a instalar más de un circuito de cualquiera de los tipos descritos en el grado de electrificación básica, así como si se hace la previsión de sistemas de calefacción eléctrica, acondicionamiento de aire, automatización, secadora, gestión técnica de la energía y seguridad o con superficies útiles de las viviendas superiores a $160 \mathrm{~m}^{2}$.

En este caso se instalarán, además de los circuitos correspondientes a la electrificación básica, los siguientes circuitos adicionales:

- C6 Circuito adicional tipo C1, por cada 30 puntos de luz.

- C7 Circuito adicional de tipo C2 por cada 20 tomas de corriente de uso general o si la superficie útil de la vivienda es mayor de $160 \mathrm{~m}^{2}$.

- C8 Circuito de distribución interna, destinado a la instalación de calefacción eléctrica, cuando exista previsión de ésta.

- C9 Circuito de distribución interna, destinado a la instalación aire acondicionado, cuando existe previsión de éste.

Tabla 5

Circuitos interiores

\begin{tabular}{|l|l|l|}
\hline CIRCUITO & SECCIÓN ( $^{2}$ ) & PIA ( Amperios ) \\
\hline Alumbrado ( a partir de $160 \mathbf{m}^{2}$ dos circuitos ) & 1,5 & 10 \\
\hline Pequeños electrodomésticos ( otros usos ) & 2,5 & 16 \\
\hline Aparatos de lavar ( lavadora, lavavajillas, secadora ) & 4 & 20 \\
\hline Aparatos de cocinar (cocina, horno, microondas, etc.) & 6 & 25 \\
\hline Secadora & 2,5 & 16 \\
\hline Circuitos para baños y cocinas & 2,5 & 16 \\
\hline Calefacción eléctrica de día ( uno o dos circuitos ) & 6 & 25 \\
\hline Calefacción por acumulación ( 1 circuito por aparato ) & $4 / 6$ & $20 / 25$ \\
\hline Aire acondicionado o bomba de calor & 6 & 25 \\
\hline Termo agua caliente & $2,5 / 4$ & $16 / 20$ \\
\hline Automatización & 1,5 & 10 \\
\hline
\end{tabular}




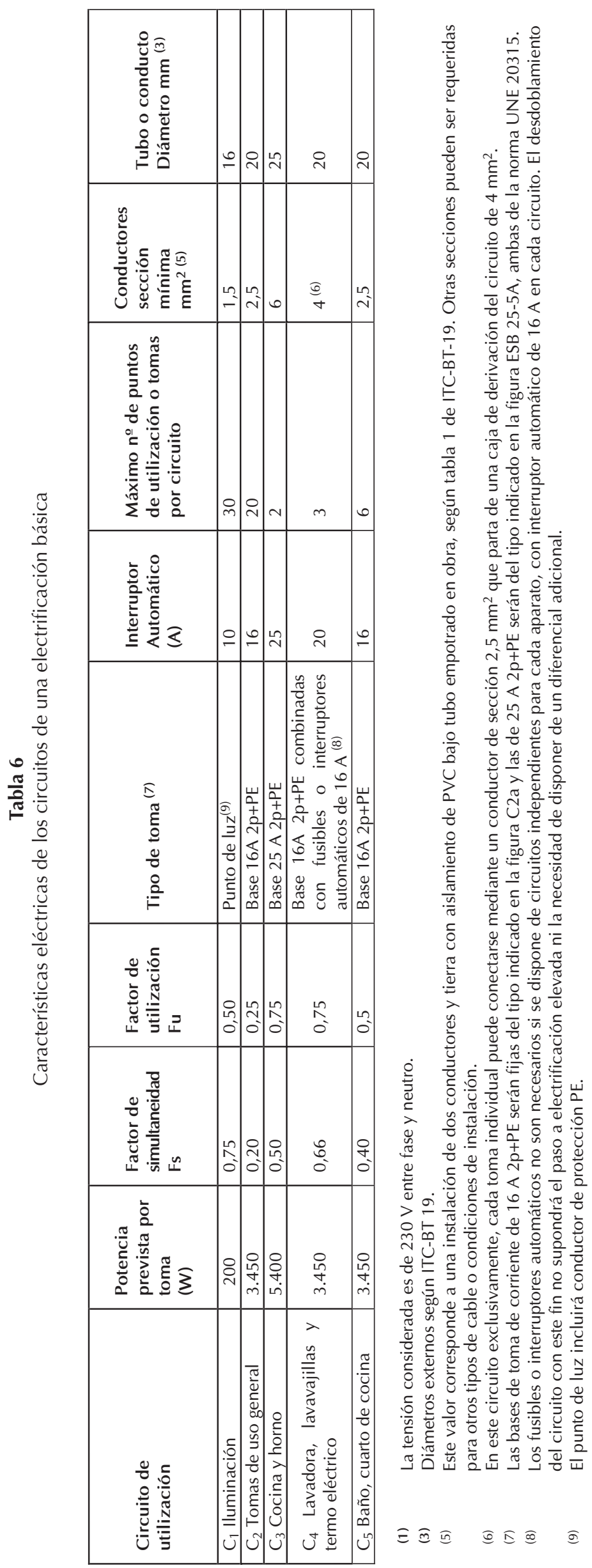




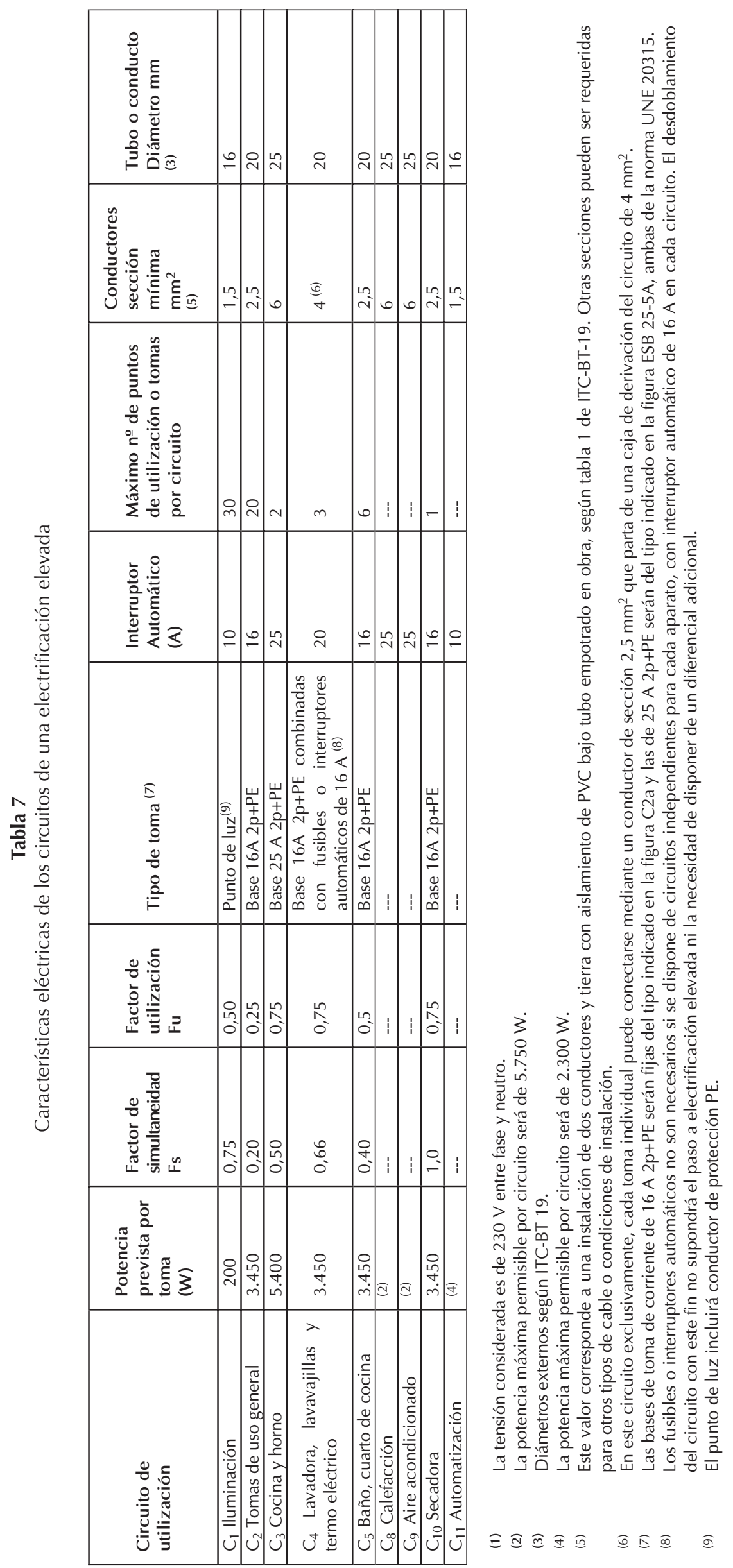


- C10 Circuito de distribución interna, destinado a la instalación de una secadora independiente.

- C11 Circuito de distribución interna, destinado a la alimentación del sistema de automatización(Domótica, seguridad, etc.).

- C12 Circuitos adicionales de cualquiera de los tipos $\mathrm{C} 3$ o $\mathrm{C} 4$, cuando se prevean, o circuito adicional del tipo C5, cuando su numero de tomas de corriente exceda de 6 .

Tanto para la electrificación básica como para la elevada, se colocará, como mínimo, un interruptor diferencial de alta sensibilidad, 30 $\mathrm{mA}$, por cada cinco circuitos instalados.

\subsubsection{Resumen de los circuitos eléctricos en} función de grado de electrificación

En las tablas 6 y 7 ha quedado expuesto el resumen de los circuitos que corresponden a cada grado de electrificación con sus características correspondientes.

\subsection{Ubicación de los circuitos eléctricos en la vivienda}

El Reglamento para Baja Tensión describe los puntos de utilización que deben de existir, como mínimo, en cada una de las estancias de una vivienda, garantizando de esta manera un mínimo de calidad a las mismas y la garantía que los futuros usuarios puedan hacer uso de los electrodomésticos mas usuales sin tener que hacer ampliaciones o modificaciones.

En la Tabla 8 se resumen los puntos de utilización, estancia por estancia.

Como se puede observar en el Reglamento Electrotécnico para Baja Tensión de 2002 aparecen los circuitos:

C8 específico para calefacción

C9 especifico para aire acondicionado

C11 especifico para domótica.

Tabla 8

Puntos de utilización mínimos en cada estancia

\begin{tabular}{|c|c|c|c|c|}
\hline Estancia & Circuito & Mecanismo & № mínimo & Superficie / Longitud \\
\hline Acceso & $\mathrm{C}_{1}$ & Pulsador - timbre & 1 & \\
\hline \multirow[t]{2}{*}{ Vestíbulo } & $\mathrm{C}_{1}$ & $\begin{array}{l}\text { Punto de luz } \\
\text { Interruptor } 10 . \mathrm{A}\end{array}$ & $\begin{array}{l}1 \\
1 \\
\end{array}$ & \begin{tabular}{|l|l}
-- \\
---
\end{tabular} \\
\hline & $\mathrm{C}_{2}$ & Base 16 A $2 p+P E$ & 1 & --- \\
\hline \multirow{4}{*}{$\begin{array}{l}\text { Sala de estar o } \\
\text { Salón }\end{array}$} & $\mathrm{C}_{1}$ & \begin{tabular}{|l|} 
Punto de luz \\
Interruptor $10 \mathrm{~A}$ \\
\end{tabular} & $\begin{array}{l}1 \\
1 \\
\end{array}$ & $\begin{array}{l}\text { hasta } 10 \mathrm{~m}^{2}\left(\text { dos si } \mathrm{S}>10 \mathrm{~m}^{2}\right) \\
\text { uno por cada punto de luz }\end{array}$ \\
\hline & $\mathrm{C}_{2}$ & Base 16 A $2 p+P E$ & $3^{(1)}$ & $\begin{array}{l}\text { una por cada } 6 \mathrm{~m}^{2} \text {, redondeado al entero } \\
\text { superior }\end{array}$ \\
\hline & $\mathrm{C}_{8}$ & Toma de Calefacción & 1 & hasta $10 \mathrm{~m}^{2}\left(\right.$ dos si $\left.\mathrm{S}>10 \mathrm{~m}^{2}\right)$ \\
\hline & $\mathrm{C}_{9}$ & Toma de Aire Acondicionado & 1 & hasta $10 \mathrm{~m}^{2}\left(\right.$ dos si $\left.\mathrm{S}>10 \mathrm{~m}^{2}\right)$ \\
\hline \multirow{4}{*}{ Dormitorios } & $\mathrm{C}_{1}$ & $\begin{array}{l}\text { Puntos de luz } \\
\text { Interruptor } 10 \mathrm{~A}\end{array}$ & $\begin{array}{l}1 \\
1 \\
\end{array}$ & $\begin{array}{l}\text { hasta } 10 \mathrm{~m}^{2}\left(\text { dos si } \mathrm{S}>10 \mathrm{~m}^{2}\right) \\
\text { uno por cada punto de luz }\end{array}$ \\
\hline & $\mathrm{C}_{2}$ & Base 16 A $2 p+P E$ & $3^{(1)}$ & $\begin{array}{l}\text { una por cada } 6 \mathrm{~m}^{2} \text {, redondeado al entero } \\
\text { superior }\end{array}$ \\
\hline & $\mathrm{C}_{8}$ & Toma de Calefacción & 1 & --- \\
\hline & $\mathrm{C}_{9}$ & Toma de Aire Acondicionado & 1 & \begin{tabular}{|c|}
--- \\
\end{tabular} \\
\hline \multirow{3}{*}{ Baños } & $\mathrm{C}_{1}$ & $\begin{array}{l}\text { Puntos de luz } \\
\text { Interruptor } 10 \mathrm{~A}\end{array}$ & $\begin{array}{l}1 \\
1\end{array}$ & --- \\
\hline & $\mathrm{C}_{5}$ & Base 16 A $2 p+P E$ & 1 & --- \\
\hline & $\mathrm{C}_{8}$ & Toma de Calefacción & 1 & --- \\
\hline \multirow{3}{*}{$\begin{array}{l}\text { Pasillos } \\
\text { distribuidores }\end{array}$} & $C_{1}$ & $\begin{array}{l}\text { Puntos de luz } \\
\text { Interruptor/Conmutador } 10 \mathrm{~A}\end{array}$ & $\begin{array}{l}1 \\
1\end{array}$ & $\begin{array}{l}\text { uno cada } 5 \mathrm{~m} \text { de longitud } \\
\text { uno en cada acceso }\end{array}$ \\
\hline & $\mathrm{C}_{2}$ & Base 16 A $2 p+P E$ & 1 & hasta $5 \mathrm{~m}$ (dos si $\mathrm{L}>5 \mathrm{~m})$ \\
\hline & $\mathrm{C}_{8}$ & Toma de Calefacción & 1 & --- \\
\hline \multirow{7}{*}{ Cocina } & $\mathrm{C}_{1}$ & \begin{tabular}{|l|} 
Puntos de luz \\
Interruptor $10 \mathrm{~A}$ \\
\end{tabular} & $\begin{array}{l}1 \\
1 \\
\end{array}$ & $\begin{array}{l}\text { hasta } 10 \mathrm{~m}^{2}\left(\text { dos si } \mathrm{S}>10 \mathrm{~m}^{2}\right) \\
\text { uno por cada punto de luz }\end{array}$ \\
\hline & $\mathrm{C}_{2}$ & Base 16 A $2 p+P E$ & 2 & extractor y frigorífico \\
\hline & $\mathrm{C}_{3}$ & Base 25 A $2 p+P E$ & 1 & cocina/horno \\
\hline & $\mathrm{C}_{4}$ & Base 16 A $2 p+P E$ & 3 & lavadora, lavavajillas y termo \\
\hline & $\mathrm{C}_{5}$ & Base 16 A $2 p+P E$ & $3^{(2)}$ & encima del plano de trabajo \\
\hline & $\mathrm{C}_{8}$ & Toma de Calefacción & 1 & --- \\
\hline & $\mathrm{C}_{10}$ & Base 16 A $2 p+P E$ & 1 & secadora \\
\hline $\begin{array}{l}\text { Terrazas } \\
\text { Vestidores } \\
\end{array}$ & $\mathrm{C}_{1}$ & \begin{tabular}{|l|} 
Puntos de luz \\
Interruptor $10 \mathrm{~A}$ \\
\end{tabular} & $\begin{array}{l}1 \\
1 \\
\end{array}$ & $\begin{array}{l}\text { hasta } 10 \mathrm{~m}^{2}\left(\text { dos si } \mathrm{S}>10 \mathrm{~m}^{2}\right) \\
\text { uno por cada punto de luz } \\
\end{array}$ \\
\hline \multirow{2}{*}{$\begin{array}{l}\text { Garajes } \\
\text { unifamiliares } \\
\text { Otros } \\
\end{array}$} & $\mathrm{C}_{1}$ & \begin{tabular}{|l|} 
Puntos de luz \\
Interruptor $10 \mathrm{~A}$ \\
\end{tabular} & \begin{tabular}{|l|l|}
1 \\
1
\end{tabular} & $\begin{array}{l}\text { hasta } 10 \mathrm{~m}^{2}\left(\text { dos si } \mathrm{S}>10 \mathrm{~m}^{2}\right) \\
\text { uno por cada punto de luz } \\
\end{array}$ \\
\hline & $\mathrm{C}_{2}$ & Base 16 A $2 p+P E$ & 1 & hasta $10 \mathrm{~m}^{2}\left(\right.$ dos si $\left.\mathrm{S}>10 \mathrm{~m}^{2}\right)$ \\
\hline
\end{tabular}

(1) En donde se prevea la instalación de una toma para el receptor de TV, la base correspondiente deberá ser múltiple, y en este caso se considerará como una sola base a los efectos del número de puntos de utilización de la tabla 1.

(2) Se colocarán fuera de un volumen delimitado por los planos verticales situados a 0,5 $\mathrm{m}$ del fregadero y de la encimera de cocción o cocina. 
11. Cuadro general para una instalación de domótica.

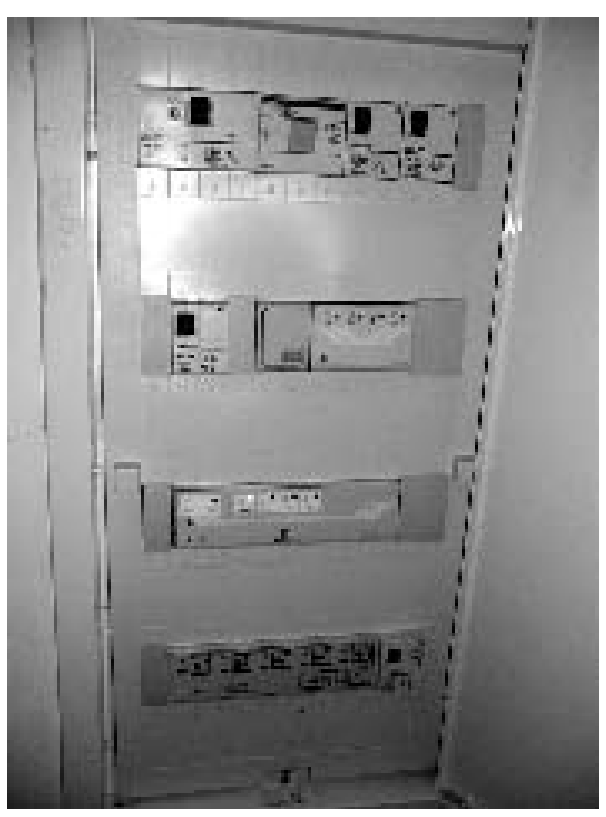

11

Que no se contemplaban en el Reglamento de 1973, y que se comentan dada su novedad:

Circuito C8: Las estancias de una vivienda donde se prevé el circuito C8 son:

\author{
Sala estar o salón \\ Dormitorios \\ Cocina \\ Baños \\ Pasillos
}

Sin entrar en un comentario especifico, es conveniente que el lector conozca la instrucción ITC BT 27 sobre instalaciones en cuartos de baño y aseo (ver punto 4.3), donde se prevé el circuito C8, y que ha sufrido grandes variaciones respecto del Reglamento de 1973.

Circuito C9: el circuito de aire acondicionado C9 se prevé en sala de estar o salón y dormitorios.

Circuito C11: el circuito C11 de domótica discurriría por todas las estancias de la vivienda.

Resaltar que en el Reglamento Electrotécnico para Baja Tensión de 2002 aparece la instrucción ITC-BT 51 destinada a las instalaciones de sistemas de automatización, gestión técnica de la energía y seguridad para viviendas y edificación, donde se establecen los requisitos específicos de la instalación de los sistemas domóticos. Se destacan algunos párrafos de esta instrucción por la importancia de los mismos y por ser novedosos ya que es la primera vez que un Reglamento describe estos sistemas:
El campo de aplicación de esta instrucción comprende las instalaciones de aquellos sistemas que realizan una función de automatización para diversos fines, como gestión de la energía, control y accionamiento de receptores de forma centralizada o remota, sistemas de emergencia y seguridad en edificios, entre otros, con excepción de aquellos sistemas independientes e instalados como tales, que puedan ser considerados en su conjunto como aparatos, por ejemplo, los sistemas automáticos de elevación de puertas, persianas, toldos, cierres comerciales, sistemas de regulación de climatización, redes privadas independientes para transmisión de datos exclusivamente y otros aparatos.

Los sistemas de Automatización, Gestión de la energía y Seguridad considerados en la presente instrucción, se clasifican en los siguientes grupos:

- Sistemas que usan en todo o en parte señales que se acoplan y transmite por la instalación eléctrica de Baja Tensión, tales como sistemas de corrientes portadoras.

- Sistemas que usan en todo o en parte señales transmitidas por cables específicos para dicha función, tales como cables de pares trenzados, paralelo, coaxial, fibra óptica.

- Sistemas que usan señales radiadas, tales como ondas de infrarrojo, radiofrecuencia, ultrasonidos o sistemas que se conec$\tan$ a la red de telecomunicaciones.

Un sistema domótico puede combinar varios de los sistemas anteriores, debiendo cumplir los requisitos aplicables en cada parte del sistema. La topología de la instalación puede ser de distintos tipo, tales como anillo, árbol, bus o lineal, estrella o combinaciones de éstas.

La guía práctica de aplicación del reglamento para Baja Tensión, de la ITC - BT 51 describe de una forma muy práctica la aplicación de estas instalaciones de automatización de las viviendas. Se puede conocer a través de la página Web del Ministerio de Industria.

\subsection{Características de los circuitos}

Los circuitos irán entubados, y por cada tubo irá el conductor de fase (los tres conductores de fase si la distribución en trifásica por necesidades del aparato eléctrico), el conductor de neutro y el conductor de protección. La sección de los conductores de neutro y de protección será igual a la sección del conductor de fase que acompañan (en circuitos monofásicos). 
Los colores normalizados para los conductores son:

Fase: negro (monofásico) y además marrón y gris (trifásico)

Neutro: Azul claro

Protección: Amarillo verde a rayas

No se permitirá el empalme de los conductores dentro de los tubos, sino en las cajas de conexión. Hay que fijar la atención en las cajas de conexiones y derivaciones, donde los conductores se unirán con elementos de presión únicamente, y nunca se empalmarán por el sistema de retorcimiento. Las tomas de corriente tendrán una capacidad de acuerdo con el electrodoméstico a conectar. Estarán provistas de toma de tierra.

Siempre que se pueda se colocarán pequeñas clavijas de conexión en los puntos de luz y siempre acompañados del conductor de protección (tierra), puesto que las lámparas, apliques, armaritos de baño, etc., suelen ser metálicos y es necesario ponerlos a tierra.

Los interruptores de los circuitos de alumbrado cortarán siempre el conductor de fase. Si es posible se deben de ir colocando interruptores bipolares que garantizan de una forma eficaz la seguridad de las personas, teniendo así la garantía de ausencia de tensión.

\subsection{Instalaciones interiores de mención especial}

Dentro de las instalaciones interiores merecen mención aparte las cocinas y los cuartos de baño, dado su potencial riesgo eléctrico tanto por el elevado número de aparatos electrodomésticos que se suelen instalar así como por simultanear el uso de agua y de electricidad. El nuevo reglamento define el circuito C5 de distribución interna, destinado a alimentar tomas de corriente de los cuartos de baño, así como las bases auxiliares del cuarto de cocina.

\subsubsection{Cocinas}

En las cocinas llegan hasta 7 circuitos:

- C1, Iluminación puntos de luz

- C2, Tomas de corriente generales y frigorífico

- C3, Cocina y horno

- C4, Lavadora, lavavajillas y termo eléctri$\mathrm{CO}$

- C5, Tomas de corriente auxiliares

- C8, Calefacción

- C10, Secadora

y se debe diseñar la instalación eléctrica de la cocina teniendo presente la coloca- ción adecuada de las tomas de corriente de los diferentes grandes electrodomésticos. Existen unas normas DIN que nos definen en cada toma de corriente la altura exacta, desde la cota del suelo, según el electrodoméstico de que se trate. No olvidar la toma de corriente para las campanas extractoras, la luz de los muebles de cocina superiores, las columnas de cocción, etc.

Colocar el suficiente número de tomas para todos los aparatos para evitar la colocación posterior de "ladrones" o alargaderas. En la zona de trabajo de las encimeras, a una altura de $1,10 \mathrm{~m}$, colocar tomas de corriente de circuito de toma de corriente

\subsubsection{Cuartos de baño y aseo}

En los cuartos de baño y aseos, según se describe en la ITC - BT 27, es necesario respetar los volúmenes $0,1,2$ y 3 de protección y prohibición que se describen en el nuevo reglamento, e instalar la red equipotencial de los cuartos de baño.

En la página siguiente se presentan los esquemas de los diferentes volúmenes de los cuartos de baño y aseo según el reglamento electrotécnico para baja tensión:

A los cuartos de baño y aseo llegan 3 circuitos:

- C1, iluminación puntos de luz

- C5, Tomas de corriente auxiliares

- C8, Calefacción

Los armaritos de baño deberán estar conectados al circuito $\mathrm{C} 5$

En el punto 3 de la ITC -BT 27 se describen los requisitos particulares para la instalación de bañeras y duchas de hidromasaje, cabinas de ducha con circuitos eléctricos y aparatos análogos, que deben de ser consultadas por el proyectista ya que describen las condiciones de instalación y normas de seguridad sobre la base de la norma UNE 60335.

En el punto 2.3 de dicha instrucción se representa un cuadro con la "elección e instalación de los materiales eléctricos" para las instalaciones en los cuartos de baño y aseo según los volúmenes.

En el apartado 5 de esta misma instrucción se representan figuras aclaratorias para la clasificación de los volúmenes

Asimismo, el nuevo reglamento de baja tensión plantea la nueva instrucción complementaria, la ITC - BT 50 sobre Instalaciones eléctricas en Saunas, que se deberá tener en cuenta en las nuevas instalaciones. 

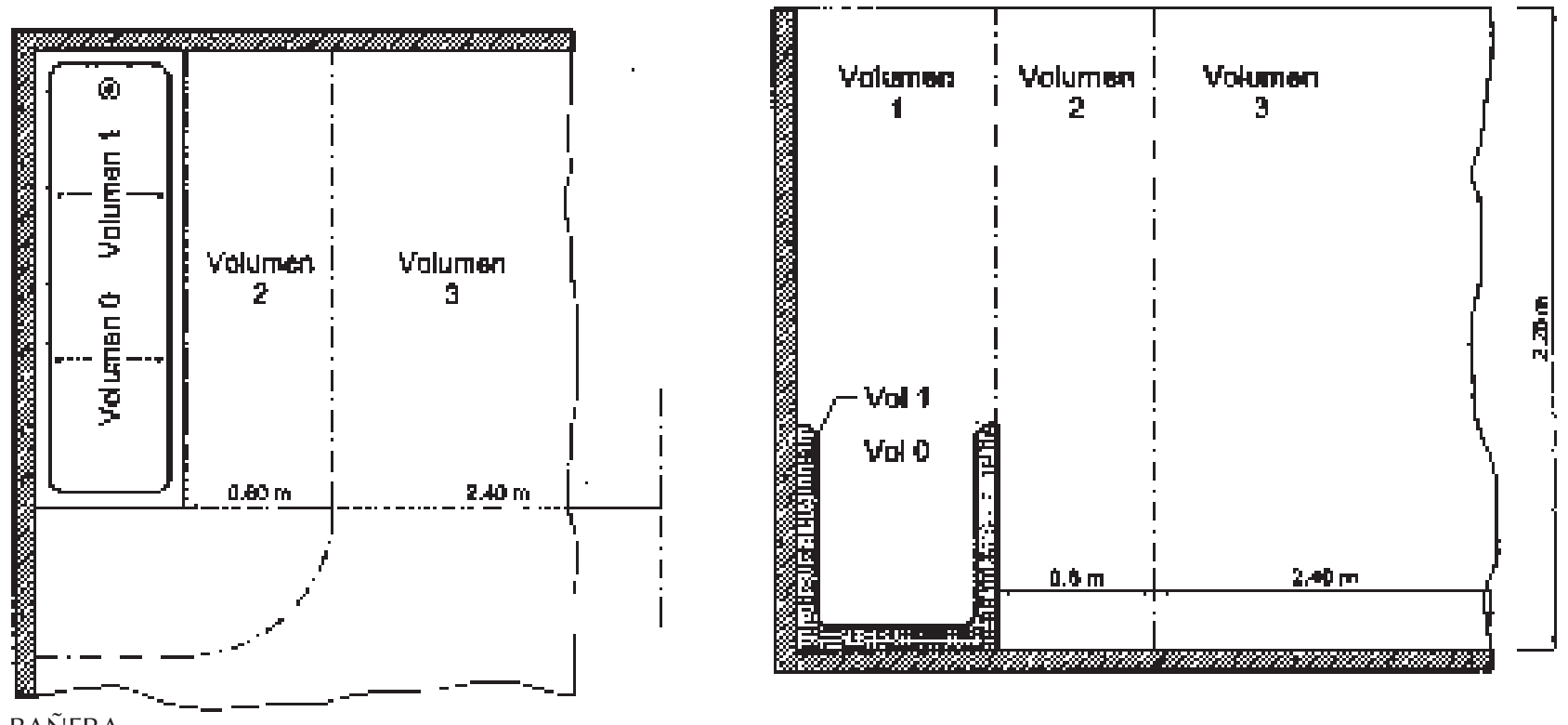

\section{BAÑERA}
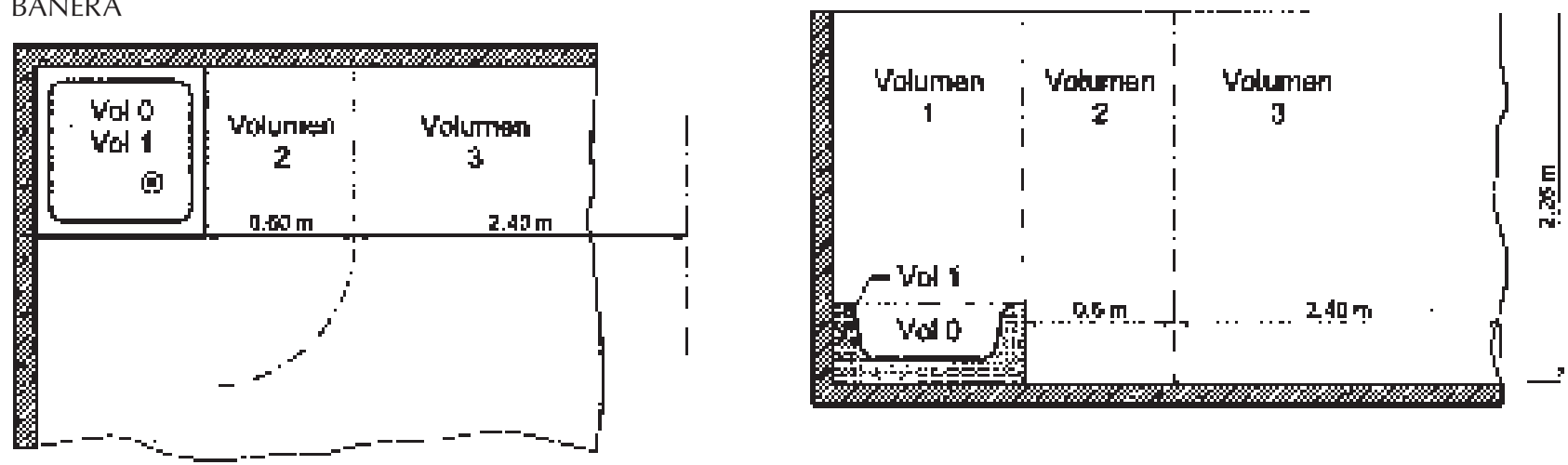

\section{DUCHAS}

\section{BIBLIOGRAFÍA}

(1) González Tirados, R. (2008). Fuentes y Normas bibliográficas para trabajos de investigación. Madrid. ICE de la Universidad Politécnica. (paper).

(2) Ministerio de Industria (1973). Reglamento electrotécnico para baja tensión. Madrid. Editorial Paraninfo.

(3) Ministerio de Industria (2002). Reglamento electrotécnico para baja tensión. Madrid. Editorial Paraninfo.

(4) Ministerio de Industria (2007). Guía de aplicación del REBT. Madrid. Editorial Paraninfo.

(5) Sanz Serrano, J.L. (2008). Instalaciones eléctricas: esquemas, aplicaciones y ejercicios. $2^{\text {a }}$ edición. Madrid. Editorial Paraninfo.

(6) Sanz Serrano, J.L. (2008). Instalaciones eléctricas: soluciones a problemas en baja y alta tensión. $2^{\text {a }}$ edición. Madrid. Editorial Paraninfo.

(7) Sanz Serrano, J.L. y TOLEDANO. J.C. (2008). Técnicas y procesos en instalaciones eléctricas en media y baja tensión. $6^{a}$ edición. Madrid. Editorial Paraninfo.

(8) Toledano, J.C. (2004). Aplicaciones y experiencias en instalaciones domóticas de viviendas y pequeños establecimientos hoteleros. Informes de la Construcción, no 494. pp. 47 - 55.

(9) Toledano, J.C. (2004). Instalaciones eléctricas en edificios destinados principalmente a viviendas. Energía, $n^{\circ}$ 177. pp $137-140$.

(10) Toledano, J.C. (2007) "Aplicaciones y experiencias en viviendas domóticas". Libro resumen de las jornadas sobre La Domótica como solución de futuro organizado por la Comunidad de Madrid. Dirección General de Industria. Madrid. pp 123 - 146.

(11) Toledano, J.C. y MARTíNEZ REQUENA, J.J. (2004). Puesta tierra en edificios y en instalaciones industriales. Madrid. Editorial Paraninfo.

(12) Toledano, J.C. y SANZ SERRANO, J.L. (2008). Instalaciones eléctricas de enlace y centros de transformación. $6^{a}$ edición. Madrid. Editorial Paraninfo.

(13) Trujillo, T. (2005). Manual de Inspección de las instalaciones eléctricas. 100 posibles fallos. Barcelona. Editorial Experiencia. 